\title{
Evaluation Methods for Final Year Practice Oriented Design Courses
}

\author{
J.A. Blatz ${ }^{1}$ and M.G. Britton ${ }^{2}$ \\ Department of Civil Engineering ${ }^{1}$ and Design Engineering ${ }^{2}$, University of Manitoba \\ blatzja@cc.umanitoba.ca and ron_britton@umanitoba.ca
}

\begin{abstract}
The curriculum debate is alive and well amongst engineering faculties across the country. Even as the Canadian Engineering Accreditation Board continues to move towards fostering more design in the curriculum the question remains as to what impacts this is having on creating practice ready engineering graduates. The term practice ready is not to imply they are ready to be registered as professionals in their jurisdiction, but is intended to imply they have enough understanding of the realities of working in the private and public sector to appreciate the many conflicting objectives and limitations organizations face when making decisions that involve a large component of engineering involvement. This paper presents a discussion of using case histories in a final year Civil Engineering course to introduce elements of institutional policy, business management and engineering practice through demonstration with case histories where decisions involved all these elements. The case histories involved discussion of legal claims and dispute resolution on projects where engineering and business considerations were weighed in concert to achieve final solutions. The class was broken into working teams to discuss the case histories at various stages where information to that point was presented. The groups reported on their position and what decisions they would take at each stage so they could appreciate how their position changed as new information became available. This paper will focus on how the curriculum material was evaluated in the context of the examinations. Given the focus around case histories, the evaluation process was difficult given any questions about the case histories covered was simply a recalling knowledge already gained. At the same time the skills to be evaluated were highly subjective and difficult to articulate in answers to specific one-off questions. As such a case study was used in the examination process with considerable success. This paper discusses the development of an examination, conducting the examination and marking the examination of a case study based problem.
\end{abstract}

\section{Introduction}

Evaluating judgement and decision making is a difficult and subjective exercise. Yet, judgement and decision making are two of the most important elements of practicing engineering and represent the highest levels of the cognitive domain (Bloom 1956). Ultimately engineering students in their final year should begin to have confidence in synthesizing results of analysis based on measured data not simply for the exercise of doing so, but to begin to evaluate options and make decisions for their clients.

The difficulty from the academic side is how can this be evaluated in the classroom in a meaningful and consistent manner that meets the academic expectations of appropriate and fair evaluations.

Recognizing there is a need for introducing practice oriented evaluation to final year students and at the same time appreciating the realities of the traditional academic environment, this paper presents an exercise where a mid-term examination was developed on the basis of an actual case history the author was involved with. This by no means is intended to suggest that this is the first time that a case history has been utilized in this manner, but it is perhaps unusual that it is being presented in the literature for others to examine.

The case history involves the design of a flood protection barrier at the crest of a riverbank slope. The application was unique in that is was unusual for permanent flood protection works to be placed at the top of the riverbank where predominantly temporary sandbag structures had been used in the past during flood events. The flood protection wall is basically a clay core dam with a segmental block wall facing system to provide an aesthetically pleasing appearance to the homes directly adjacent to the wall. The design and construction were completed using accepted practices and were proceeding as anticipated until midway through the installation when movements were measured with an instrument that appeared 
consistent with what would be observed in a traditional global slope instability (the riverbank falling into the river). This us where the examination begins.

\section{Examination Design}

In order to utilize a case history one must first have the experience with the case history or have a well documented case history to familiarize themselves with. In this particular situation, one of the authors was retained by the lead consultant to review the design of the flood wall to identify if anything had been unintentionally missed in the original design. This is mentioned only because it is a reminder of the value of having academic staff involved in consulting activities in the local community. This is a unique consideration in most professional schools where involvement in practicing ones profession provides 'war stories' for the classroom and a more intimate understanding of the challenges faces by practicing engineers in terms of limitations in design and analytical methods that can often open doors to potential research opportunities.

Once the case history has been identified, the main learning objective to be evaluated must be clear. In the particular course under consideration, the main focus was on qualitative risk management and understanding the business aspects of engineering practice. What made this case history particularly interesting as an evaluation tool is that the construction of a permanent flood protection wall on the riverbank crest was unusual and as such included a large amount of monitoring which provided a large data set for students to examine. This provided the opportunity for them to apply their knowledge and comprehension of soil mechanics to examine the information and then led them to undertake simple analysis to examine what the data represented.

The second aspect that was particularly interesting was that the flood protection wall was being built by a government body funded by a time limited government program that would hand over ownership to the residents protected by the structure following a set period once the wall was completed. This resulted in very interesting dynamics between the parties (lead consultant, contractor, owner (government at the time) and future owners (resident)) in terms of how risks were being evaluated.

Based on those two unique aspects to the case history the fundamental questions provided on the examination were:
1. In your opinion, why are the movements occurring and what can be done to stop them? What questions (and to whom) might you ask to build increased confidence on your opinion of why the movements are occurring?

2. Based on your opinion of why the movements are occurring, what are the risks to the parties involved and what would you recommend to mitigate those risks if you were representing each of them in turn?

\subsection{Examination Format}

The examination opens with a detailed background of the site and the timeline of events leading up to the problem. A balance must be drawn to provide enough information to give an adequate picture of the site but not so much as to bog the student down with reading when the primary focus of the examination is thinking and responding. In this case data and plots of measurements from the site were provided along with the plan and elevation view of the location where the movements were noted. Figure 1 shows an example page with a plan view and photograph of the site.

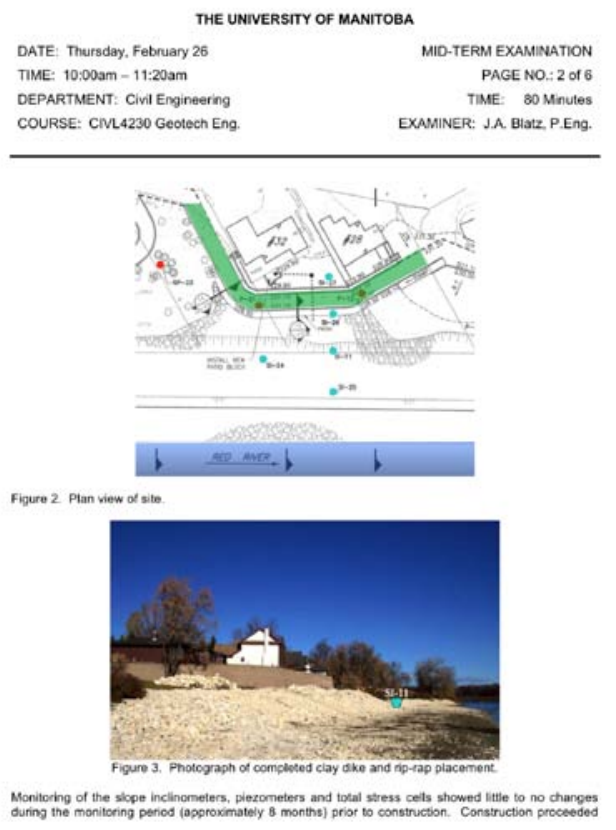

Figure 1. Typical Examination Figures

Although after the fact some of the data is know not to be relevant to the problem that was solved, it is important not to filter that out when recreating the experience for the students as at the time of the failure, there was no basis to rule any information out 
immediately. This also avoided the potential for the information provided to lead the students to what the actual response was.

\subsection{Free Form Response}

Once the background information and data was presented, the two very simple questions were posed. Students were provided the opportunity to provide their responses in free form format using whatever structure they felt would be most appropriate for their response. Most students chose to use headings and some bulleted points within each of the responses.

\section{Evaluation}

The evaluation of the student responses was the most difficult task to plan. This was a particularly dangerous form of examination given the lack of specific tasks being laid out before the student. The need for the students to identify what form the answer needed to take and what information was relevant for the response was in itself one of the aspects being examined. As such the following approach was adopted to ensure fairness in the evaluation process.

1. Defining the Questions - The students were told clearly prior to the examination what the two questions were and that they would be required to formulate a response that demonstrated the use of engineering judgement and the knowledge they had gained in prior courses. There was no downside to providing the questions in advance as they were meaningless in the context of not knowing what the case history was. However, providing the questions gave the students a sense of expectation as to what they would be responding to and helped them prepare for the exam that would otherwise be very difficult to predict. As a result they generally had a plan of attack going into the examination as to what form they would use to provide their response. They also had a sense of what material they felt they needed to study to be prepared for whatever case history might be presented. A key in this was preparing the students for the experience of having to provide an opinion supported by facts and apply judgment in the assessment of risk to the parties involved in the case history. Some guidance was also provided in showing another case history example to give them a sense as to what type of information and background would be provided.

2. Setting Expectations for Response - given the very subjective nature of the information and the fact that even with the data provided there would be a number of potential answers the class was guided through the case studies provided during the classes to develop the capability to rationally defend opinions developed on facts. This provided the framework for them to work from when answering the first question on the examination as to the cause of the movements where they would have to clearly defend the position put forward.

3. Understanding Risk - The second question required a clear development of the understanding of risk from various perspectives (business, regulatory body, government, client, consultant) and required a clear understanding of how to define risk. Students were shown through the case histories in the class how to identify the probability of an event and the consequence were that even to occur. This gave them the first opportunity (from the authors perspective) to view engineering decisions in the context of the many other considerations at hand.

4. The Marks - Students were told explicitly that the two questions were worth equal marks (20 each) and full marks would be achieved if the mechanism identified in part one was defended appropriately on the basis of the facts presented. This was very important as it provided some reduction of concern amongst the students if they got the mechanism wrong the results of the second question would immediately be incorrect (double jeopardy). As a result students felt comfortable to provide their own opinion knowing that as long as they argued it correctly on the basis of the information provided it would not be penalized.

The 'answer' (what actually transpired) to the case history was written up in advance and held in a sealed envelope for the students to review following the examination. The solution was written in the form generally followed in presenting the case studies during the term in the regular course slots. 


\section{Discussion of the Evaluation}

The exam garnered considerable excitement amongst the students. The interest in bringing their own case histories identified in the literature to have the author review and provide comment on was unexpected. However the value that was being gained by the students in the process of studying by finding these case studies was probably something they were not aware of. Every case study they identified and studied added to the course content and to their own 'experience'. The students also began to show development of a value in the literature not seen previously. As they began to explore case histories through searchers they began to realize how valuable it was to identify documented cases previously encountered when working within the practicing environment. It was also clear that they recognized the considerable importance in communication as part of the self-study process as they worked in large groups bounding ideas off each other as they worked through the case histories gathered. The focus was on thinking and defending positions rather than the nuances of the details of each example. As the authors observed this, it began to become clear that a majority of the benefit of being so transparent about the test content and expectations is that the students study habits created an environment of team learning as all recognized there was no upper hand available to guess what the questions might be and no secrecy with materials to study as everyone had something to offer in the discussions.

The examination was time limited as traditionally done but the material was expected to be completed within the timeframe allotted. Approximately $90 \%$ of the students finished prior to the end of the time. As per usual, there were a large group of students at the exit to the exam room following the examination discussing answers and arguing as to what the most likely answer was.

When grading the papers it became clear that a majority of the students identified the traditional expectation that the riverbank was failing (moving) due to the added surcharge load of placing the flood protection wall at the crest of the slope. As a result most students identified that the consultant had a considerable risk as that would be expected to be a core design issue that would have been analyzed in detail and as such if the riverbank was in fact moving it would likely be due to a design error or changed conditions from the original design. A small number of student proposed other mechanisms such as the river level changing to quickly (there was a graph showing the river level did fluctuate), incorrect testing and a few other plausible reasons. Provided the risks identified by the students to the parties involved were compatible with the cause of the movements that were occurring then full marks were assessed. In fact, the spectrum of answers provided that were considered plausible were all plausible causes discussed in the design office the afternoon the movements occurred and an emergency meeting was held to find out what was occurring. Given the 100 plus years of experience amongst the 6 or 7 people in that room considering the same various mechanisms as potentially plausible the author felt it appropriate to award the students full marks for identifying the same potential issues.

The risks to the parties involved fell directly out of the cause identified by each individual student and generally were handled very well. This was somewhat surprising given this was a first exposure to qualitatively identifying risks for stakeholders outside of engineering interests but were clearly being dictated by an engineering issue.

In the end two students identified the actual cause of the movements that were determined in the actual investigation. The cause was that the movement indicator happened to be in a location relative to the load placement were the location and form of movement that occurred was simply displacement in response to applied load of adding the flood wall. The movements then ceased following the load application and the riverbank was stable. Being the first time a major permanent structure had been placed on a marginally stable riverbank, this behaviour had not previously been identified.

The students were extremely positive on the reviews of the course and when asked explicitly about the examination process they generally indicated they enjoyed the opportunity to have their decision making ability tested without any risk of being responsible for the situation described. It was apparent that the experience of being evaluated in this manner provided them with some new confidence on their abilities to use their engineering knowledge in a rationale and defensible manner while keeping the considerations of all stakeholders involved at hand

\section{References}

[1] Bloom, B.S. (ed.) (1956) Taxonomy of Educational Objectives, the classification of educational goals - Handbook I: Cognitive Domain New York: McKay. 